\title{
Environmental technological choice in a Cournot-Bertrand model
}

\author{
Elias Asproudis* and Eleftherios Filippiadis*** \\ *University of Swansea, Swansea, UK, Ilias.Asproudis@swansea.ac.uk, +44 1792606823 \\ **University of Macedonia, Thessaloniki, Greece, efilipp@uom.edu.gr, +30 2310891770
}

\begin{abstract}
This paper investigates the abatement technology choice in a CournotBertrand duopoly where the regulator has imposed a per unit of emission tax. It is argued that, under certain conditions, the Bertrand firm will choose a "dirtier" technology compared to its Cournot rival. Moreover, the introduction of abatement technologies will increase total output in the market and decrease total emissions.

Keywords: Oligopoly theory; environment; technological choice; competition; Cournot-Bertrand

JEL classification numbers: Q5; Q55; C72; D01; L13

${ }^{*}$ Correspondence: Eleftherios Filippiadis, University of Macedonia, School of Economic and Regional Studies, Nea Egnatia 154, 51300, Thessaloniki, Greece. email: efilipp@uom.edu.gr tel.:
\end{abstract} $+302310891770$ 


\section{Introduction}

There has been a rising interest in the IO literature in types of competition where the same competing firms choose, within a specific market, different strategic variables. A firm's choice of strategic variable is not solely determined by market attributes, but it also depends on the characteristics of the individual production processes. Kreps and Scheinkman (1983) has shown that when production precedes demand realization a firm chooses quantity as its strategic variable (i.e., the firm is a Cournot competitor). On the other hand, when production schedules can be easily changed, a firm chooses price as its strategic instrument (i.e., the firm is a Bertrand competitor). Therefore, it is conceivable that firms operating in the same market but characterized by significantly different production processes might choose different strategic instruments. Empirical observations confirm the existence of this type of oligopolies. Tremblay and Tremblay (2011) mentions the small car industry example where Honda and Subaru dealers decide upon quantities while Scion and Saturn dealers decide upon prices, whereas Sato (1996) is discussing the case of the Japanese domestic market of electronics where Matsushita and Sanyo are acting as Cournot and Bertrand rivals, respectively.

Oligopolies of this type have been theoretically explored in Singh and Vives $(1984)^{1}$ where the Cournot-Bertrand duopoly is analysed and compared against pure Cournot and Bertrand models under the assumptions of constant marginal costs, zero fixed costs, and no capacity limitations. These authors conclude that each firm's dominant strategy is to compete à la Cournot. However, as pointed out in Tremblay and Tremblay (2011) this conclusion rests on the assumption of zero fixed cost and the choice of the strategic instrument might change should this assumption change. This study explores the effect product differentiation has on the optimal decision making under Cournot-Bertrand competition and argues that the equilibrium is stable for a sufficient degree of product differentiation and that the Cournot-Bertrand outcomes can be optimal. A more recent study (Tremblay and Tremblay, 2017) investigates the effect an excise tax has on prices in pure Cournot, Bertrand, and Cournot-Bertrand

\footnotetext{
${ }^{1}$ See also Häckner (2000), Arya et al. (2008), and Tremblay et al. (2013).
} 
models, fully describing the conditions under which firms can undershift or overshift the tax onto the consumers. Furthermore, Naimzada and Tramontana (2012) focuses on the dynamic case of the Cournot- Bertrand duopoly while Manasakis and Vlassis (2014) presents a case of upstream-downstream pair-wise firms where downstream firms compete in Cournot, Bertrand, and/or Cournot-Bertrand fashion. Similarly, Rosanova (2017) studies equilibrium wholesale prices in vertically related firms with Cournot-Bertrand competition in the final product market. It concludes that "at the downstream level the Bertrand-type competitor has a cost advantage over the Cournot-type firm."

In earlier studies Matsumoto and Onozaki (2005) and Yousefi and Szidarovszky (2005) modeled the complex dynamics of mixed duopolies with nonlinear demands. Wang and Ma (2013) consider a Cournot-Bertrand model with bounded rationality expectations and explore equilibria and local stability under limited information. Also, Ma and Pu (2013) explores the complex characteristics of a mixed CournotBertrand model using nonlinear dynamics theory. Matsumoto and Szidarovszky (2010) investigate the continuous dynamics of mixed Cournot-Bertrand competition without time delays, and with fixed and continuously distributed time lags. They argue that fixed time lags have a larger destabilizing effect on the dynamics than continuously distributed time lags. Matsumoto and Szidarovszky (2011) focus on $\mathrm{N}$-firm Cournot-Bertrand competition and conclude that "... i i]f the firms can precommit to quantity or price strategy, the dominant strategy depends on the average quality ratio of the goods produced by the quantity-adjusting firms and the goods produced by the price-adjusting firms." Szidarovszky and Molnar (1992) focus on the general oligopoly Cournot-Bertrand model with nonlinear complementarity problem and the existence and uniqueness of the Nash equilibrium. Chang et al. (2015) examines the case of the Cournot-Bertrand model under the existence of patent licensing and differentiated duopoly. Tremblay and Tremblay (2019) offers a comprehensive review of the related literature and examines the alternative market conditions under which the Cournot-Bertrand model can emerge. It also discusses the welfare ranking of Cournot-Bertrand oligopoly compared to pure Cournot and pure Bertrand oligopolies. The authors propose the application of the Cournot-Bertrand model in 
areas of economics such as international economics, industrial organization, labor, and public economics.

While the specific characteristics of the Cournot-Bertrand model have been analyzed in the literature there is still little research done on how firms, engaging in this type of competition, respond to environmental policies. This paper investigates the choice of abatement technology in a static Cournot-Bertrand duopoly and its effect on quantities, prices, profits, and emissions. We argue that, for a reasonably wide range of demand and cost parameters, the Cournot firm will choose a "greener" technology compared to its Bertrand rival. At the same time, it will produce more, charge less and yield higher profits compared to the Bertrand firm. This is because investing in abatement technology effectively lowers the per unit of production effluent tax for the firm making it more aggressive in the product market competition. Furthermore, starting from the same level of anti-pollution technology an identical improvement in the abatement technology increases the supply of the Cournot firm by more than the increase in the supply of its Bertrand rival, hence making the Cournot firm relatively more aggressive than the Bertrand firm.

Moreover, we show that when a range of abatement technologies is available to the firms the total output in the market will increase while total emissions decrease, thus increasing consumer welfare. This result is also confirmed in pure Cournot and pure Bertrand oligopolies. Finally, we show that firms choose a greener technology when engage in quantity competition (i.e., pure Cournot) than in price competition (i.e., pure Bertrand). In Section 2 we develop the Cournot-Bertrand model in the presence of emission taxes and abatement technology choice, and we derive the relevant results. In Section 3 we conduct the same analysis for the pure Cournot and pure Bertrand oligopolies and we extend our findings on the connection between abatement technology choice and the type of competition. In addition, we provide some numerical results on welfare comparisons between the different types of oligopolies. Finally, Section 4 concludes. 


\section{The model}

Following Tremblay and Tremblay (2011), we consider a Cournot-Bertrand oligopoly market where two firms $i=1,2$ produce a differentiated product. Without loss of generality, we assume that firm 1's strategic variable is quantity facing an inverse demand

$$
p_{1}=(1-d) a-\left(1-d^{2}\right) q_{1}+d p_{2}
$$

while firm 2's strategic variable is price facing a demand

$$
q_{2}=a-p_{2}-d q_{1}
$$

where $a>0$ represents the size of the market and $d \in(0,1)$ represents the degree of product differentiation. $^{2}$

Both firms' costs are assumed equal to zero, without loss of generality. The production process generates emissions $e_{i}$ at a rate of one emissions unit for each unit of output. The regulator taxes emissions at a rate $t>0$ thus creating an additional cost $T=t e_{i}$ to each firm. Both firms have access to a technology allowing the reduction of the emissions rate per unit of output from 1 to $k_{i} \in[0,1]$ at a cost $C A_{i}=\gamma\left(1-k_{i}\right)^{2}$, where $\gamma>0$ is a scale parameter. This cost represents diminishing returns to investment in environmental technology. ${ }^{3}$ The closer to unit the value of technology $k_{i}$ is, the lower the adoption cost and the more polluting the technology will be (see also Asproudis and Gil Molto, 2014 and 2015, and Asproudis et al. 2018). Hence, there is a trade-off between the cost of adapting greener technology and the reduced amount of the environmental tax. Furthermore, the actual emissions of firm $i$ are $e_{i}=k_{i} q_{i}$. In this set up firm $i$ 's total cost function is given by

$$
C_{i}=\gamma\left(1-k_{i}\right)^{2}+t k_{i} q_{i}
$$

\footnotetext{
${ }^{2}$ We are not considering the trivial case of two independent monopolies, i.e. $d=0$. Also excluded from our analysis is the case of a homogeneous product, i.e. $d=1$.

${ }^{3}$ In our case the technological choice is irrelevant (at least directly) to the production process. For example, the anti-pollution technology could be the number of the filters in the pipe or the catalysts in the exhaust for the restraint of the particulate matters or carbon emissions.
} 
and the corresponding profit function is

$$
\Pi_{i}=p_{i} q_{i}-\gamma\left(1-k_{i}\right)^{2}-t k_{i} q_{i}
$$

Competition in this model can be described as a two-stage game. Prior to the first stage, the regulator chooses ad-hoc the environmental tax. At the first stage, firms choose their anti-pollution technologies. At the second stage, given the observable choices made in the first stage, firms compete in the output market. For the remainder of Section 2 we are adopting the following restrictions:

$$
\gamma>\widehat{\gamma}=\frac{2 t^{2}}{4-3 d^{2}}
$$

and

$$
a>\widehat{a}=\frac{4-d\left(2+2 d-2 d^{2}-d^{3}\right)}{\left(1-d^{2}\right)\left(2-2 d+d^{2}\right)} t>2 t
$$

The former is sufficient to ensure positivity of the market outcomes and the latter non-negativity of the technological indexes. We are adopting these constraints throughout Section 2 of this paper.

\subsection{Stage 2: Firms compete in the output market}

Given their anti-pollution technology, firms maximize their profits, as expressed by (4), by optimally choosing the level of output $q_{1}$ (firm 1) and price $p_{2}$ (firm 2). The first order conditions (FOCs) ${ }^{4}$ of the profit maximization problems yield the following reaction functions:

$$
\begin{gathered}
q_{1}^{R F}=\frac{a(1-d)+d p_{2}-t k_{1}}{2\left(1-d^{2}\right)} \\
p_{2}^{R F}=\frac{1}{2}\left(a-d q_{1}+t k_{2}\right)
\end{gathered}
$$

Interestingly, differentiating the above reaction functions with respect to the re-

\footnotetext{
${ }^{4}$ The Second Order Conditions (SOCs) are satisfied since $\frac{\partial^{2} \Pi_{i}}{\partial q_{i}^{2}}=2\left(d^{2}-1\right)<0, \forall d \in(0,1)$.
} 
spective technologies yields $\partial q_{1}^{R F} / \partial k_{1}=-t /\left(2\left(1-d^{2}\right)\right)<0$ and $\partial p_{2}^{R F} / \partial k_{2}=t / 2>$ $0^{5}$ which implies the fact that by adopting a "greener" technology a firm becomes more aggressive, i.e., increase the quantity willing to offer in the market for any given choice of its rival. ${ }^{6}$ Furthermore, since $\left|\partial q_{1}^{R F} / \partial k_{1}\right|>\left|\left(\partial q_{2} / \partial p_{2}^{R F}\right)\left(\partial p_{2}^{R F} / \partial k_{2}\right)\right|$, starting from the same level of anti-pollution technology an equal reduction in $k$ increases the supply of firm 1 by more than the increase in the supply of firm 2 , hence making firm 1 relatively more aggressive than firm 2 .

Solving simultaneously the system of the reaction functions (5), (6) we obtain

$$
\begin{gathered}
q_{1}=\frac{a(2-d)-\left(2 k_{1}-d k_{2}\right) t}{4-3 d^{2}} \\
p_{2}=\frac{a\left(2-d-d^{2}\right)+\left(2\left(1-d^{2}\right) k_{2}+d k_{1}\right) t}{4-3 d^{2}}
\end{gathered}
$$

Substituting the above in (1), (2), and (4) we get

$$
\begin{gathered}
p_{1}=\frac{a\left(2-d-2 d^{2}+d^{3}\right)+\left(\left(2-d^{2}\right) k_{1}+d\left(1-d^{2}\right) k_{2}\right) t}{4-3 d^{2}} \\
q_{2}=\frac{a\left(2-d-d^{2}\right)+\left(d k_{1}-\left(2-d^{2}\right) k_{2}\right) t}{4-3 d^{2}} \\
\Pi_{1}=\left(1-d^{2}\right)\left(\frac{a(2-d)-\left(2 k_{1}-d k_{2}\right) t}{4-3 d^{2}}\right)^{2}-\gamma\left(1-k_{1}\right)^{2} \\
\Pi_{2}=\left(\frac{a\left(2-d^{2}-d\right)+\left(d k_{1}-\left(2-d^{2}\right) k_{2}\right) t}{4-3 d^{2}}\right)^{2}-\gamma\left(1-k_{2}\right)^{2}
\end{gathered}
$$

Replacing $k_{1}=k_{2}=1$ in the above expressions yields the respective quantities, prices, and profits if no anti-pollution technology is adopted, namely $q_{i}^{o}, p_{i}^{o}$, and $\Pi_{i}^{o}, i=1,2$. Moreover, it is straightforward to confirm that in the absence of antipollution technology $q_{1}^{o}>q_{2}^{o}, p_{1}^{o}<p_{2}^{o}$, and $\Pi_{1}^{o}>\Pi_{2}^{o}$, i.e., the Cournot firm produces more, charges less and obtains higher profits compared to its Bertrand rival.

\footnotetext{
${ }^{5}$ From the demand function of firm 2 we get $\left(\partial q_{2} / \partial p_{2}^{R F}\right)=1$. Therefore, $\partial q_{2} / \partial k_{2}=$ $\left(\partial q_{2} / \partial p_{2}^{R F}\right)\left(\partial p_{2}^{R F} / \partial k_{2}\right)=-t / 2<0$.

${ }^{6}$ The reader should be reminded here that lower $k_{i}$ implies greener technology.
} 


\subsection{Stage 1: Firms choose technology}

In stage 1 firms 1 and 2 are maximizing their profits, expressed by equations (11) and (12), by optimally choosing their respective technological parameter, $k_{i}$. Profit maximization yields the following reaction functions

$$
\begin{gathered}
k_{1}^{R F}=\frac{\gamma\left(4-3 d^{2}\right)^{2}-2 t\left(1-d^{2}\right)\left(2 a-a d+d t k_{2}\right)}{\gamma\left(4-3 d^{2}\right)^{2}-4 t^{2}\left(1-d^{2}\right)} \\
k_{2}^{R F}=\frac{\gamma\left(4-3 d^{2}\right)^{2}-t\left(2-d^{2}\right)\left(a\left(2-d-d^{2}\right)+d t k_{1}\right)}{\gamma\left(4-3 d^{2}\right)^{2}-t^{2}\left(2-d^{2}\right)^{2}}
\end{gathered}
$$

Under the assumption that $\gamma>\widehat{\gamma}$ both reaction functions are negatively sloped implying that $k_{1}$ and $k_{2}$ are strategic substitutes to each other. Solving simultaneously the reaction functions system in (13), (14) we obtain

$$
\begin{aligned}
& k_{1}^{*}=1-\frac{2\left(1-d^{2}\right)\left((2-d)\left(4-3 d^{2}\right) \gamma-\left(2-d^{2}\right) t^{2}\right)(a-t) t}{\left(4-3 d^{2}\right)\left(\left(4-3 d^{2}\right)^{2} \gamma^{2}-\left(8-8 d^{2}+d^{4}\right) \gamma t^{2}\right)+2\left(2-3 d^{2}+d^{2}\right) t^{4}} \\
& k_{2}^{*}=1-\frac{(1-d)\left(2-d^{2}\right)\left((2+d)\left(4-3 d^{2}\right) \gamma-2(1+d) t^{2}\right)(a-t) t}{\left(4-3 d^{2}\right)\left(\left(4-3 d^{2}\right)^{2} \gamma^{2}-\left(8-8 d^{2}+d^{4}\right) \gamma t^{2}\right)+2\left(2-3 d^{2}+d^{2}\right) t^{4}}
\end{aligned}
$$

Substituting $k_{1}^{*}$ and $k_{2}^{*}$ in equations $(7),(8),(9),(10),(11)$ and (12) we can get the output level, the price and the profits of each firm, respectively.

\subsection{Results}

In this section we first explore the firms' choices of anti-pollution technologies as well as their resulting levels of production, prices, and profits. We state the following

Proposition 1 Let $d \in(0,1), t>0, a>\widehat{a}>2 t$, and $\gamma>\widehat{\gamma}$. Then the Cournot firm is choosing a greener anti-pollution technology, producing more, charging less and earning higher profits compared to its Bertrand rival, i.e., 
(a) $k_{1}^{*}-k_{2}^{*}<0$

(b) $q_{1}^{*}-q_{2}^{*}>0$,

(c) $p_{1}^{*}-p_{2}^{*}<0$, and

(d) $\Pi_{1}^{*}-\Pi_{2}^{*}>0$.

Proof. See the appendix.

The result of Proposition 1 can be intuitively explained: investing in abatement technology in the fist stage effectively lowers the per unit of production effluent tax for the firm making it more aggressive in the product market competition. As explained earlier, firm 1 becomes relatively more aggressive than firm 2. This strategic advantage of the Cournot firm implies that it will invest more on abatement technology and, consequently, produce more, charge less, and earn higher profits compared to its Bertrand rival.

While a full welfare analysis is analytically intractable we examine the implications from introducing abatement technologies on consumer welfare. We state the following

Corollary 2 Let $d \in(0,1), t>0, a>\widehat{a}>2 t, \gamma>\widehat{\gamma}$, and $k_{1}^{*}-k_{2}^{*}<0$. Then the availability of an abatement technology in the industry will result in (i) $q_{1}^{*}+q_{2}^{*}>$ $q_{1}^{o}+q_{2}^{o}$, and (ii) $e_{1}^{*}+e_{2}^{*}<e_{1}^{o}+e_{2}^{o}$.

The first part of Corollary 2 shows that the introduction of anti-pollution technologies increases the competition between the two firms resulting in higher total output in the market. The second part of Corollary 2 shows that the introduction of anti-pollution technologies reduces total emissions despite its positive effect in total output. Higher output and lower emissions imply that consumer welfare increases with the availability of anti-pollution technology. 


\section{Cournot and Bertrand Oligopolies}

In this section we consider the choice of abatement technology in case where (a) the two firms simultaneously choose quantities (i.e., pure Cournot), and (b) the two firms simultaneously choose prices (i.e., pure Bertrand). The demand and inverse demand functions of the two firms in the Bertrand and Cournot duopolies are, respectively:

$$
\begin{gathered}
q_{i}=\frac{(1-d) a-p_{i}+d p_{-i}}{1-d^{2}}, \\
p_{i}=a-q_{i}-d q_{-i},
\end{gathered}
$$

where $i=1,2$. As in the previous section the stage where the two firms simultaneously choose abatement technologies precedes the stage of final product market competition, whether the latter is a la Cournot or a la Bertrand. The following two subsections summarize the analytical results.

\subsection{Cournot}

Solving for the Subgame Perfect Nash Equilibrium in the pure Cournot model yields the optimal level of abatement technology for firm $i=1,2^{7}$ in Stage 1 :

$$
k_{i}^{C *}=1-\frac{2 t(a-t)}{(2-d)(2+d)^{2} \gamma-2 t^{2}}
$$

Substituting $k_{i}^{C *}$ into the relevant equations of Stage 2 yield the output level $q_{i}^{C *}$, the price $p_{i}^{C *}$, the emissions $e_{i}^{C *}$, and the profits $\Pi_{i}^{C *}$ of each firm. Let also $q_{i}^{C o}, p_{i}^{C o}$, $e_{i}^{C o}$, and $\Pi_{i}^{C o}$ indicate the quantity, the price, the emissions, and the profits, respectively, when no anti-pollution technology is available. Our findings are summarized

\footnotetext{
${ }^{7}$ Note that the pure Cournot oligopoly is symmetric.
} 
in Table 1.

\begin{tabular}{|c|c|}
\hline Technology is available & Technology is not available \\
\hline \hline$k_{i}^{C *}=1-\frac{2 t(a-t)}{(2-d)(2+d)^{2} \gamma-2 t^{2}}$ & $k_{i}^{C o}=1$ \\
\hline$q_{i}^{C *}=\frac{\left(4-d^{2}\right)(a-t) \gamma}{(2-d)(2+d)^{2} \gamma-2 t^{2}}$ & $q_{i}^{C o}=\frac{a-t}{2+d}$ \\
\hline$p_{i}^{C *}=\frac{\left(4-d^{2}\right)(a+(1+d) t) \gamma-2 a t^{2}}{(2-d)(2+d)^{2} \gamma-2 t^{2}}$ & $p_{i}^{C o}=\frac{a+t+d t}{2+d}$ \\
\hline$\Pi_{i}^{C *}=\frac{\gamma(a-t)^{2}\left(\left(-4+d^{2}\right)^{2} \gamma-4 t^{2}\right)}{\left((2-d)(2+d)^{2} \gamma-2 t^{2}\right)^{2}}$ & $\Pi_{i}^{C o}=\left(\frac{a-t}{2+d}\right)^{2}$ \\
\hline$e_{i}^{C *}=\frac{\left(4-d^{2}\right)\left((2-d)(2+d)^{2} \gamma-2 a t\right)(a-t) \gamma}{\left((2-d)(2+d)^{2} \gamma-2 t^{2}\right)^{2}}$ & $e_{i}^{C o}=\frac{a-t}{2+d}$ \\
\hline Table 1: pure Cournot outcomes & \\
\hline
\end{tabular}

Note that second order condition of the profit maximization in Stage 1 requires $\gamma>\widehat{\widehat{\gamma}}=4 t^{2} /\left(4-d^{2}\right)^{2}$.

\subsection{Bertrand}

Solving for the Subgame Perfect Nash Equilibrium in the pure Bertrand model yields the optimal level of abatement technology for firm $i=1,2^{8}$ in Stage 1 :

$$
k_{i}^{B *}=1-\frac{\left(2-d^{2}\right)(a-t) t}{(2-d)^{2}(1+d)(2+d) \gamma-\left(2-d^{2}\right) t^{2}}
$$

Substituting $k_{i}^{B *}$ into the relevant equations of Stage 2 yield the output level $q_{i}^{B *}$, the price $p_{i}^{B *}$, the emissions $e_{i}^{B *}$, and the profits $\Pi_{i}^{B *}$ of each firm. Let also $q_{i}^{B o}, p_{i}^{B o}$, $e_{i}^{B o}$, and $\Pi_{i}^{B o}$ indicate the quantity, the price, the emissions, and the profits, respectively, when no anti-pollution technology is available. Our findings are summarized

\footnotetext{
${ }^{8}$ Note that the pure Bertrand oligopoly is symmetric.
} 
in Table 2.

\begin{tabular}{|c|c|}
\hline Technology is available & Technology is not available \\
\hline \hline$k_{i}^{B *}=1-\frac{\left(2-d^{2}\right)(a-t) t}{(2-d)^{2}(1+d)(2+d) \gamma-\left(2-d^{2}\right) t^{2}}$ & $k_{i}^{B o}=1$ \\
\hline$q_{i}^{B *}=\frac{\left(4-d^{2}\right)(a-t) \gamma}{(2-d)^{2}(1+d)(2+d) \gamma-\left(2-d^{2}\right) t^{2}}$ & $q_{i}^{B o}=\frac{a-t}{2+d-d^{2}}$ \\
\hline$p_{i}^{B *}=\frac{\left(4-d^{2}\right)(1+d)((1-d) a+t) \gamma-a\left(2-d^{2}\right) t^{2}}{(2-d)^{2}(1+d)(2+d) \gamma-\left(2-d^{2}\right) t^{2}}$ & $p_{i}^{B o}=\frac{a-a d+t}{2-d}$ \\
\hline$\Pi_{i}^{B *}=\frac{\left(\left(4-d^{2}\right)^{2}\left(1-d^{2}\right) \gamma-\left(2-d^{2}\right)^{2} t^{2}\right)(a-t)^{2} \gamma}{\left((2-d)^{2}(1+d)(2+d) \gamma-\left(2-d^{2}\right) t^{2}\right)^{2}}$ & $\Pi_{i}^{B o}=\frac{(1-d)(a-t)^{2}}{(1+d)(2-d)^{2}}$ \\
\hline$e_{i}^{B *}=\frac{\left(4-d^{2}\right)\left((2-d)^{2}(1+d)(2+d) \gamma-a\left(2-d^{2}\right) t\right)(a-t) \gamma}{\left((2-d)(2+d)^{2} \gamma-2 t^{2}\right)^{2}}$ & $e_{i}^{B o}=\frac{a-t}{2+d-d^{2}}$ \\
\hline Table 2: pure Bertrand outcomes &
\end{tabular}

Note that second order condition of the profit maximization in Stage 1 requires $\gamma>\widetilde{\widetilde{\gamma}}=\left(2-d^{2}\right)^{2} t^{2} /\left(\left(1-d^{2}\right)\left(4-d^{2}\right)^{2}\right)$.

\subsection{Results}

In this section we first explore the firms' choices of anti-pollution technologies in pure Cournot compared to pure Bertrand oligopoly. We state the following

Proposition 3 Let $d \in(0,1), t>0, a>2 t$, and $\gamma>\widetilde{\widetilde{\gamma}}>\widehat{\widehat{\gamma}}$. Then the firms in a pure Cournot oligopoly are choosing a greener anti-pollution technology than in a pure Bertrand oligopoly, i.e., $k_{i}^{C *}-k_{i}^{B *}<0$.

Proof. See the appendix.

The intutive explanation of Proposition 3 is similar to that of proposition 1. Starting from the same anti-pollution technology, an identical improvement in abatement technology will increase the supplies of Cournot rivals by more than the increase in supplies of Berttrand rivals, ${ }^{9}$ hence making Cournot firms relatively more aggressive than Bertrand firms.

\footnotetext{
${ }^{9}$ It can be shown that in the second stage of pure Cournot and pure Bertrand oligopolies we get we get $\partial q_{i}^{C R F} / \partial k_{i}=-t / 2<0$ and $\partial p_{i}^{B R F} / \partial k_{i}=t / 2>0 \Rightarrow\left(\partial q_{i} / \partial p_{i}^{B R F}\right)\left(\partial p_{i}^{B R F} / \partial k_{i}\right)=$ $-\left(1-d^{2}\right) t / 2<0$, correspondingly. Hence $\left|\partial q_{i}^{C R F} / \partial k_{i}\right|>\left|\left(\partial q_{i} / \partial p_{i}^{B R F}\right)\left(\partial p_{i}^{B R F} / \partial k_{i}\right)\right|$.
} 
Furthermore, we examine the implications from introducing abatement technologies on consumer welfare in Cournot and Bertrand oligopolies. We state the following

Corollary 4 Let $d \in(0,1), t>0$ and $a>2 t$. Also, let $\gamma>\frac{4 t^{2}}{\left(4-d^{2}\right)^{2}}$ for the Cournot Oligopoly $\left(\gamma>\frac{\left(2-d^{2}\right) t^{2}}{\left(1-d^{2}\right)\left(4-d^{2}\right)^{2}}\right.$ for the Bertrand oligopoly). Then the availability of an abatement technology in the Cournot (Bertrand) industry will result in (i) $q_{i}^{C *}>q_{i}^{C o}$ $\left(q_{i}^{B *}>q_{i}^{B o}\right)$, and (ii) $e_{i}^{C *}<e_{i}^{C o}\left(q_{i}^{B *}>q_{i}^{B o}\right)$.

The first part of Corollary 4 shows that the introduction of anti-pollution technologies increases the competition between the two firms in a pure oligopoly resulting in higher total output in the market. The second part of Corollary 4 shows that, for the optimal level of anti-pollution technology, the rate of abatement exceeds the rate at which production increases. Hence, the overall pollution decreases. Similar to the Cournot-Bertrand oligopoly, the availability of anti-pollution technology in pure Cournot and pure Bertrand oligopolies increases consumer welfare.

We also compare

(i) the anti-pollution choice of the Cournot (Bertrand) firm in the Cournot-Bertrand oligopoly with that of a firm in pure Cournot, and

(ii) the anti-pollution choice of the Bertrand firm in the Cournot-Bertrand oligopoly with that of a firm in pure Bertrand.

We could not derive an analytical result with respect to (i). However, numerical analysis shows that the lower the degree of product differentiation is and the higher $\gamma$ is, it is more likely that the Cournot firm in pure Cournot oligopoly will choose a greener abatement technology compared to the Cournot rival in the CournotBertrand oligopoly. This is illustrated in Figure 1 where the difference $k_{1}^{*}-k_{i}^{C *}$ is drawn as a function of $d$, for $a=1000, t=2$, and three different values of $\gamma$.

With respect to (ii) we state the following

Proposition 5 Let $d \in(0,1), t>0, a>2 t$, and $\gamma>\widetilde{\widetilde{\gamma}}>\widehat{\widehat{\gamma}}$. Then a firm in pure Bertrand oligopoly is choosing a greener anti-pollution technology than a Bertrand rival in the Cournot-Bertrand oligopoly, i.e., $k_{i}^{B *}-k_{2}^{*}<0$. 


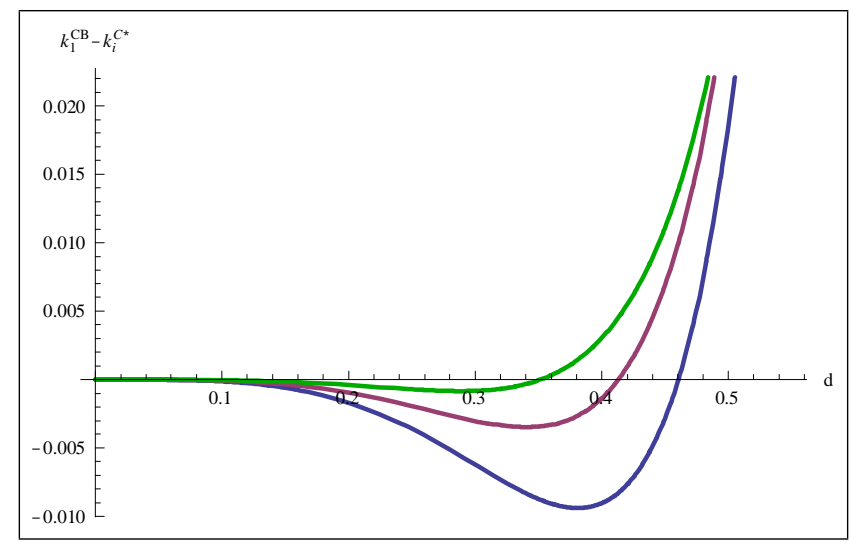

Figure 1: Comparison on abatement technologies between the Cournot firm in Cournot-Bertrand and a firm in pure Cournot: $\gamma=8$ (blue line), $\gamma=10$ (red line) and $\gamma=14$ (green line).

Proof. See the appendix.

This section concludes with a numerical illustration of our findings. To include welfare comparisons we assume that environmental damage is a quadratic function of total emissions, i.e.,

$$
E D=\rho\left(e_{1}+e_{2}\right)^{2}
$$

where $\rho>0$ is a parameter of perceived environmental damage and $e_{i}=k_{i} q_{i}$ denotes the actual emissions of a firm. We set the parameter values as follows: $a=100$, $t=2, \gamma=60, d=0.5$, and $\rho=1$. Table 3 summarizes the results for the three different types of competition confirming our findings. 


\begin{tabular}{c|ccc} 
& Cournot & Bertrand & Cournot-Bertrand \\
\hline \hline$k_{1}$ & 0.293057 & 0.312969 & 0.294021 \\
$k_{2}$ & 0.293057 & 0.312969 & 0.314113 \\
$q_{1}$ & 39.7656 & 44.1662 & 45.8886 \\
$q_{2}$ & 39.7656 & 44.1662 & 38.2137 \\
$p_{1}$ & 40.3517 & 33.7506 & 35.0045 \\
$p_{2}$ & 40.3517 & 33.7506 & 38.842 \\
$\Pi_{1}$ & 1551.31 & 1434.67 & 1549.42 \\
$\Pi_{2}$ & 1551.31 & 1434.67 & 1432.06 \\
$P S$ & 3102.62 & 2869.34 & 2981.48 \\
$C S$ & 2371.95 & 2925.99 & 2659.82 \\
$T R$ & 46.6143 & 55.2907 & 50.9913 \\
$E D$ & 543.222 & 764.267 & 650.028 \\
$W$ & 4977.97 & 5086.36 & 5042.26 \\
\hline$T$
\end{tabular}

Table 3: Summary of results

It is worth to be noted that the three types of oligopoly cannot be welfare ranked in the presence of quadratic environmental damages. Table 4 provides welfare results for $a=100, t=2, \gamma=60, d=0.5$, and different values of $\rho$ and the repective welfare rankings.

\begin{tabular}{c|ccc|l}
\multicolumn{2}{c}{$W^{C}$} & $W^{B}$ & \multicolumn{1}{c}{$W^{C B}$} & \multicolumn{1}{c}{ Ranking } \\
\hline \hline$\rho=1.0$ & 4977.97 & 5086.36 & 5042.26 & $W^{B}>W^{C B}>W^{C}$ \\
$\rho=1.5$ & 4706.36 & 4704.22 & 4717.25 & $W^{C B}>W^{C}>W^{B}$ \\
$\rho=2.0$ & 4434.74 & 4322.09 & 4392.23 & $W^{C}>W^{C B}>W^{B}$ \\
\hline
\end{tabular}

Table 4: Welfare result of the three oligopolies

\section{Conclusions}

The present paper analyses the abatement technology choice in a two-stage duopoly with choice of technology at the first stage and three different types of competition at the second stage, namely, Cournot-Bertrand, pure Cournot, and pure Bertrand. 
In the first stage the two firms unilaterally decide upon adopting some anti-pollution technology, e.g., the number of the catalysts or the filters for the restraint of the emissions and then they compete in the output market. Our analysis shows that the Bertrand firm chooses dirtier technology than its Cournot rival, while the latter produces more, charges less and earns higher profits. Furthermore, when competing in quantities (Cournot) firms choose greener technologies than when competing in prices (Bertrand). This is because higher abatement rates make a firm choosing quantity relatively more aggressive than a firm choosing price, irrespective of the strategic variable of its rival.

Moreover, it is shown that the introduction of abatement technologies increases total output in the market and decreases total emissions, thus increasing consumer welfare. Full welfare analysis is analytically intractable in our model. However, using numerical analysis we show that the three types of oligopolies cannot be welfare ranked.

Our analysis in the present paper focuses only on environmental taxes. However, we are currently investigating other environmental policy instruments (e.g., tradeable emission permits, emission standards) and their effect on the Cournot-Bertrand competition in comparison with the pure Cournot and pure Bertrand respectively. 


\section{References}

1. Arya, A., Mittendorf, B. and Sappington, D.E.M. (2008). Outsourcing, vertical integration, and price vs. quantity competition. International Journal of Industrial Organization, 26, 1-16.

2. Asproudis, E. and Gil-Moltó, M. J. (2015). Green trade unions: Structure, wages and environmental technology. Environmental and Resource Economics, $60,165-189$.

3. Asproudis, E. and Gil-Moltó, M. J. (2014). Pollution and environmentalists participation in Emissions Trading Systems. Strategic Behavior and the Environment, 4, 59-87.

4. Asproudis, E., Khan, N. and Korac-Kakabadse, N. (2018). Game of Regional Environmental Policy: Europe and US. Journal of Industry, Competition and Trade, https://doi.org/10.1007/s10842-018-0274-7

5. Chang, R. Y., Lin, Y. S. and Hu, J. L. (2015). Mixed competition and patent licensing. Australian Economic Papers, 54, 229-249.

6. Häckner, J. (2000). A note on price and quantity competition in differentiated oligopolies. Journal of Economic Theory, 93, 233-239.

7. Kreps, D., Scheinkman, J. (1983). Quantity Precommitment and Bertrand Competition Yield Cournot Outcomes. Bell Journal of Economics, 14, 326338.

8. Ma, J. and Pu, X. (2013). The research on Cournot-Bertrand duopoly model with heterogeneous goods and its complex characteristics. Nonlinear Dynamics. $72,895-903$

9. Manasakis, C. and Vlassis, M. (2014). Downstream Mode of Competition With Upstream Market Power. Research in Economics, 68, 84-93. 
10. Matsumoto, A. and Onozaki, T. (2005). Heterogenous Strategies in Nonlinear Duopoly with Product Differentiation. Pure Mathematics and Applications, $16,443-466$.

11. Matsumoto, A. and Szidarovszky, F. (2010). Delayed dynamics in heterogeneous competition with product differentiation. Nonlinear Analysis: Real World Applications, 11, 601-611.

12. Matsumoto, A. and Szidarovszky, F. (2011). Mixed Cournot-Bertrand competition in N-firm differentiated oligopolies, Unpublished manuscript, Department of Economics, Chuo University, Tokyo

13. Naimzada, A.K. and Tramontana, F. (2012). Dynamic properties of a CournotBertrand duopoly game with differentiated products. Economic Modelling, 29, 1436-1439.

14. Rozanova, O. (2017). Wholesale prices and Cournot-Bertrand competition. Bulletin of Economic Research, 69, E12-E18.

15. Sato, T. (1996). On Cournot-Bertrand mixed duopolies. Japanese Economic Review, 47, 412-420.

16. Singh, N. and Vives, X. (1984). Price and quantity competition in a differentiated oligopoly. RAND Journal of Economics, 15, 546-554.

17. Szidarovszky, F. and Molnár, F. (1992). Bertrand, Cournot and mixed oligopolies, Keio Economic Studies, 29, 1-7.

18. Tremblay, C. H. and Tremblay, V. J. (2011). The Cournot-Bertrand Model and the degree of product differentiation. Economic Letters, 111, 233-235.

19. Tremblay, V. J., Tremblay, C. H. and Isariyawongse, K. (2013). Endogenous timing and strategic choice: The Cournot-Bertrand model. Bulletin of Economic Research, 65, 332-342. 
20. Tremblay, M. J. and Tremblay, V. J. (2017). Tax incidence and Demand Convexity in Cournot, Bertrand, and Cournot-Bertrand models. Public Finance Review, 45, 748-770.

21. Tremblay, C. H. and Tremblay, V. J. (2019). Oligopoly Games And The Cournot-Bertrand Model: A Survey. Journal of Economic Surveys, 33, 15551577. doi:10.1111/joes.12336

22. Wang, H. and Ma, J. (2013). Complexity analysis of a Cournot-Bertrand duopoly game model with limited information. Discrete Dynamics in Nature and Society, Article ID 287371, 1-6 .

23. Yousefi, S. and Szidarovszky, F. (2005). One more on price and quantity competition in differentiated duopolies: A simulation study. Pure Mathematics and Applications, 16, 515-531. 


\section{Appendix}

Proof of Proposition 1. We calculate the following difference

$$
k_{1}^{*}-k_{2}^{*}=\frac{-A \gamma t d^{3}(a-t)(1-d)}{B}
$$

where $B=\gamma^{2}\left(4-3 d^{2}\right)^{3}-\gamma\left(4-3 d^{2}\right)\left(8-8 d^{2}+d^{4}\right) t^{2}+2\left(2-3 d^{2}+d^{4}\right) t^{4}$. Given $d \in(0,1)$ and $a>\widehat{a}>2 t$ the numerator of the above difference is negative. Therefore, it suffices to show that $B>0$. We get $B>-\gamma t^{2}\left(4-3 d^{2}\right)\left(8-8 d^{2}+d^{4}\right)+$ $\gamma^{2}\left(4-3 d^{2}\right)^{3}=\gamma\left(4-3 d^{2}\right)\left(\gamma\left(4-3 d^{2}\right)^{2}-t^{2}\left(8-8 d^{2}+d^{4}\right)\right)$. However, by assumption $\gamma>\frac{2 t^{2}}{4-3 d^{2}} \Rightarrow \gamma\left(4-3 d^{2}\right)\left(\gamma\left(4-3 d^{2}\right)^{2}-t^{2}\left(8-8 d^{2}+d^{4}\right)\right)>\gamma\left(4-3 d^{2}\right)\left(2 t^{2}\left(4-3 d^{2}\right)-t^{2}(8-8 d\right.$ $\gamma d^{2} t^{2}\left(4-3 d^{2}\right)\left(2-d^{2}\right)>0$. Hence $B>0$.

In addition, we calculate the following differences

$$
\begin{gathered}
q_{1}^{*}-q_{2}^{*}=\frac{\gamma A d^{2}(a-t)\left(\gamma A-t^{2}\right)}{B} \\
p_{1}^{*}-p_{2}^{*}=\frac{\gamma d^{2} A(1-d)(a-t)\left(t^{2}-A \gamma\right)}{B} \\
\Pi_{1}^{*}-\Pi_{2}^{*}=\frac{\gamma d^{3} A(1-d)(a-t)^{2}\left(t^{2}-A \gamma\right)\left((1+d)\left(8-4 d-4 d^{2}+d^{3}\right) t^{2}-2 A^{2} \gamma\right)}{B^{2}}
\end{gathered}
$$

As proven above the denominators in (18), (19), and (20) are positive. Moreover,

- the numerator in (18) is positive since $a>t$, and, by assumption, $\gamma>\frac{2 t^{2}}{4-3 d^{2}} \Rightarrow$ $\gamma A>2 t^{2}>t^{2}$. Therefore, $q_{1}^{*}-q_{2}^{*}>0$.

- the numerator in (19) is negative since all the factors are positive except the last one, where $\gamma>\frac{2 t^{2}}{4-3 d^{2}} \Rightarrow 0>2 t^{2}-\gamma A \Rightarrow 0>t^{2}-\gamma A$. Therefore, $p_{1}^{*}-p_{2}^{*}<0$.

- the numerator in (20) is positive since $(1-d)>0,(a-t)^{2}>0, t^{2}-\gamma A<0$, and $(1+d)\left(8-4 d-4 d^{2}+d^{3}\right) t^{2}-2 A^{2} \gamma<\left(8-4 d-4 d^{2}+d^{3}\right) t^{2}-2 A^{2} \gamma<$ $4 A t^{2}-2 A^{2} \gamma=2 A\left(2 t^{2}-\gamma A\right)<0$. Therefore, $\Pi_{1}^{*}-\Pi_{2}^{*}>0$. 
Proof of Corollary 2. (i) We get

$$
\left(q_{1}^{*}+q_{2}^{*}\right)-\left(q_{1}^{o}+q_{2}^{o}\right)=\frac{\left(2-k_{1}-k_{2}\right)(2-d) t-d^{2}\left(1-k_{2}\right) t}{\left(4-3 d^{2}\right)}
$$

Note that, since $0<d<1$, the denominator is positive. Therefore, the sign of this difference depends on the sign of the numerator. We must show that $\left(2-k_{1}-k_{2}\right)(2-d) t-$ $d^{2}\left(1-k_{2}\right) t>0 \Rightarrow\left(2-k_{1}-k_{2}\right)(2-d)-d^{2}\left(1-k_{2}\right)>0 \Rightarrow\left(2-k_{1}-k_{2}\right)(2-d)>$ $d^{2}\left(1-k_{2}\right) \Rightarrow \frac{\left(2-k_{1}-k_{2}\right)}{\left(1-k_{2}\right)}>\frac{d^{2}}{(2-d)}$. However, due to $k_{1}<k_{2}$ we get

$$
\begin{aligned}
& \frac{\left(2-k_{1}-k_{2}\right)}{\left(1-k_{2}\right)}>\frac{2\left(1-k_{2}\right)}{\left(1-k_{2}\right)}>\frac{d^{2}}{(2-d)} \Rightarrow \\
& \frac{\left(2-k_{1}-k_{2}\right)}{\left(1-k_{2}\right)}>2>\frac{d^{2}}{(2-d)}
\end{aligned}
$$

(ii) We get

$$
\begin{gathered}
\left(e_{1}^{*}+e_{2}^{*}\right)-\left(e_{1}^{o}+e_{2}^{o}\right)= \\
=\frac{a\left(4-2 d-d^{2}-2 k_{1}-2 k_{2}+d k_{2}+d^{2} k_{2}+d k_{1}\right)-t\left(4-2 d-d^{2}-2 k_{1}^{2}+d^{2} k_{2}^{2}-2 k_{2}^{2}+2 d k_{1} k_{2}\right)}{3 d^{2}-4}
\end{gathered}
$$

Note that the denominator is negative. We denote $M$ the numerator of the above expression. Given that $a>2 t$ and $4-2 d-d^{2}-2 k_{1}-2 k_{2}+d k_{1}+d k_{2}+d^{2} k_{2}>0$ we get

$$
\begin{gathered}
M>2 t\left(-2 d-2 k_{1}-2 k_{2}+d k_{1}+d k_{2}+d^{2} k_{2}-d^{2}+4\right)+ \\
+t\left(2 d-d^{2} k_{2}^{2}+2 k_{1}^{2}+2 k_{2}^{2}+d^{2}-2 d k_{1} k_{2}-4\right)= \\
=t\left(4-2 d-d^{2}-d^{2} k_{2}^{2}-2 d k_{1} k_{2}-4 k_{1}-4 k_{2}+2 d k_{1}+2 k_{1}^{2}+2 k_{2}^{2}+2 d k_{2}+2 d^{2} k_{2}\right)> \\
>t\left(2 k_{1}+4 k_{2}-d^{2} k_{2}^{2}-2 d k_{1}-2 d k_{2}+2 k_{1}^{2}+2 k_{2}^{2}-2 d^{2} k_{2}-2 d k_{1} k_{2}\right)> \\
>t\left(2 k_{1}^{2}+2 k_{2}^{2}-2 d k_{1} k_{2}-d^{2} k_{2}^{2}\right)+2 t\left(2-d^{2}-d\right) k_{2}>0
\end{gathered}
$$


Proof of Proposition 3. We calculate the following difference

$$
k_{i}^{C *}-k_{i}^{B *}=-\frac{d^{3}\left(4-d^{2}\right) \gamma(a-t) t}{\left[(2-d)(2+d)^{2} \gamma-2 t^{2}\right] \times \Gamma}
$$

where $\Gamma=(2-d)^{2}(1+d)(2+d) \gamma-\left(2-d^{2}\right) t^{2}$. Given $d \in(0,1)$ and $a>t$ the numerator of the above difference is positive. Therefore, it suffices to show that the denominator is also positive. Note that

$$
\gamma>\frac{\left(2-d^{2}\right)^{2} t^{2}}{\left(4-d^{2}\right)^{2}\left(1-d^{2}\right)}
$$

Hence,

- the left term in brackets in the denominator is positive since

$$
\frac{2\left(4-d^{2}\right)^{2}\left(1-d^{2}\right)}{\left(2-d^{2}\right)^{2}} \gamma=\frac{2\left(1-d^{2}\right)(2-d)}{\left(2-d^{2}\right)^{2}}(2-d)(2+d)^{2} \gamma>2 t^{2}
$$

But

$$
\begin{gathered}
-2\left(d^{2}+1\right)<d^{3} \Rightarrow \\
4-2 d-4 d^{2}-2 d^{3}<d^{4}-4 d^{2}+4 \Rightarrow \\
2\left(1-d^{2}\right)(2-d)<\left(2-d^{2}\right)^{2} \Rightarrow \\
\frac{2\left(1-d^{2}\right)(2-d)}{\left(2-d^{2}\right)^{2}}<1
\end{gathered}
$$

Therefore,

$$
\begin{gathered}
(2-d)(2+d)^{2} \gamma>\frac{2\left(1-d^{2}\right)(2-d)}{\left(2-d^{2}\right)^{2}}(2-d)(2+d)^{2} \gamma>2 t^{2} \Rightarrow \\
(2-d)(2+d)^{2} \gamma-2 t^{2}>0
\end{gathered}
$$


- $\Gamma$ is positive since

$$
\frac{\left(4-d^{2}\right)\left(1-d^{2}\right)}{\left(2-d^{2}\right)} \gamma=\frac{(2+d)(1-d)}{\left(2-d^{2}\right)}(2-d)^{2}(2+d)(1+d) \gamma>\left(2-d^{2}\right) t^{2}
$$

But

$$
\begin{gathered}
d>0 \Rightarrow d^{2}+d-2>d^{2}-2 \Rightarrow-(2+d)(1-d)>-\left(2-d^{2}\right) \Rightarrow \\
\frac{(2+d)(1-d)}{\left(2-d^{2}\right)}<1
\end{gathered}
$$

Therefore,

$$
\begin{gathered}
(2-d)^{2}(2+d)(1+d) \gamma>\frac{(2+d)(1-d)}{\left(2-d^{2}\right)}(2-d)^{2}(2+d)(1+d) \gamma \Rightarrow \\
(2-d)^{2}(2+d)(1+d) \gamma>\left(2-d^{2}\right) t^{2} \\
(2-d)^{2}(1+d)(2+d) \gamma-\left(2-d^{2}\right) t^{2}
\end{gathered}
$$

\section{Proof of Corollary 4.}

- Cournot oligopoly: (i) We get

$$
q_{i}^{C *}-q_{i}^{C o}=\frac{(a-t) 2 t^{2}}{(2-d)(2+d)^{3} \gamma-2(2+d) t^{2}}
$$

Note that, since $a>t$ the numerator is positive. Therefore, it suffices to show that the denominator is also positive. Note that

$$
\begin{gathered}
\gamma>\frac{4 t^{2}}{\left(4-d^{2}\right)^{2}} \Rightarrow\left(4-d^{2}\right)^{2} \gamma>4 t^{2}>\left(4-d^{2}\right) t^{2} \Rightarrow \\
2(2+d)^{2}(2-d) \gamma>2(2+d) t^{2} \Rightarrow \frac{2}{(2+d)}(2+d)^{3}(2-d) \gamma>2(2+d) t^{2}
\end{gathered}
$$


But $2 /(2+d)<1$. Therefore,

$$
(2-d)(2+d)^{3} \gamma>2(2+d) t^{2} \Rightarrow(2-d)(2+d)^{3} \gamma-2(2+d) t^{2}
$$

(ii) We get

$$
e_{i}^{C *}-e_{i}^{C o}=-\frac{2(a-t) t\left[(a-2 t)(2-d)(2+d)^{2} \gamma+2 t^{3}\right]}{(2+d)\left[(2-d)(2+d)^{2} \gamma-2 t^{2}\right]^{2}}
$$

Note that the denominator is positive as a product of a square by a positive number. Moreover, since $a>2 t$ and $d \in(0,1)$ all the terms of the numerator are positive. Therefore, the ratio is negative due to the negative sign.

- Bertrand oligopoly: (i) We get

$$
q_{i}^{B *}-q_{i}^{B o}=\frac{\left(2-d^{2}\right)(a-t) t^{2}}{(2-d)(1+d)\left[(2-d)^{2}(2+d)(1+d) \gamma-\left(2-d^{2}\right) t^{2}\right]}
$$

Since $a>t$ and $d \in(0,1)$ the numerator is positive. Moreover, $(2-d)(1+d)>$ 0 . Therefore, it suffices to show that the term in brackets in the denominator is also positive. Note that

$$
\begin{gathered}
\gamma>\frac{4 t^{2}}{\left(4-d^{2}\right)^{2}} \Rightarrow\left(4-d^{2}\right)^{2} \gamma>4 t^{2}>\left(4-d^{2}\right) t^{2} \Rightarrow \\
\frac{\left(4-d^{2}\right)\left(1-d^{2}\right)}{\left(2-d^{2}\right)} \gamma=\frac{(2+d)(1-d)}{\left(2-d^{2}\right)}(2-d)^{2}(2+d)(1+d) \gamma>\left(2-d^{2}\right) t^{2}
\end{gathered}
$$

But

$$
\begin{gathered}
d>0 \Rightarrow d^{2}+d-2>d^{2}-2 \Rightarrow-(2+d)(1-d)>-\left(2-d^{2}\right) \Rightarrow \\
\frac{(2+d)(1-d)}{\left(2-d^{2}\right)}<1
\end{gathered}
$$


Therefore,

$$
\begin{gathered}
(2-d)^{2}(2+d)(1+d) \gamma>\frac{(2+d)(1-d)}{\left(2-d^{2}\right)}(2-d)^{2}(2+d)(1+d) \gamma \Rightarrow \\
(2-d)^{2}(2+d)(1+d) \gamma>\left(2-d^{2}\right) t^{2}
\end{gathered}
$$

(ii) We get

$$
e_{i}^{B *}-e_{i}^{B o}=-\frac{\left.\left(2-d^{2}\right)(a-t) t\left[(a-2 t)(2-d)^{2}(2+d)(1+d) \gamma+\left(2-d^{2}\right) t^{3}\right)\right]}{(2-d)(1+d)\left[(2-d)^{2}(2+d)(1+d) \gamma-\left(2-d^{2}\right) t^{2}\right]^{2}}
$$

Note that the denominator is positive as a product of a square by a positive number.

Moreover, since $a>2 t$ and $d \in(0,1)$ all the terms of the numerator are positive.

Therefore, the ratio is negative due to the negative sign.

Proof of Proposition 5. We calculate the following difference

$$
k_{i}^{B *}-k_{2}^{*}=-\frac{d^{4}\left(2-d^{2}\right) \gamma(a-t) t\left(d^{2}\left(4-3 d^{2}\right) \gamma+\left(2-d-2 d^{2}\right) t^{2}\right)}{\Gamma \times \Delta}
$$

where $\Delta=\left(4-3 d^{2}\right) \gamma\left(\left(4-3 d^{2}\right)^{2} \gamma-\left(8-8 d^{2}+d^{4}\right) t^{2}\right)+2\left(2-3 d^{2}+d^{2}\right) t^{4}$, and $\Gamma=(2-d)^{2}(1+d)(2+d) \gamma-\left(2-d^{2}\right) t^{2}$. Note the all the terms in the numerator are positive. Therefore, it suffices to show that the denominator is also positive. In the proof of proposition 3 it is shown that $\Gamma>0$. Note that

$$
\Delta>\left(4-3 d^{2}\right) \gamma\left(\left(4-3 d^{2}\right)^{2} \gamma-\left(8-8 d^{2}+d^{4}\right) t^{2}\right)>\gamma\left(\left(4-3 d^{2}\right)^{2} \gamma-\left(8-8 d^{2}+d^{4}\right) t^{2}\right)
$$

Therefore,

$$
\operatorname{sign} \Delta=\operatorname{sign}\left[\left(4-3 d^{2}\right)^{2} \gamma-\left(8-8 d^{2}+d^{4}\right) t^{2}\right]
$$

But

$$
\begin{aligned}
& \left(4-3 d^{2}\right)^{2} \gamma-\left(8-8 d^{2}+d^{4}\right) t^{2}>\left(\left(4-3 d^{2}\right)^{2}-d^{6}\right) \gamma-\left(8-8 d^{2}+d^{4}\right) t^{2} \Rightarrow \\
& \left(4-3 d^{2}\right)^{2} \gamma-\left(8-8 d^{2}+d^{4}\right) t^{2}>\left(1-d^{2}\right)\left(4-d^{2}\right)^{2} \gamma-\left(8-8 d^{2}+d^{4}\right) t^{2} \Rightarrow
\end{aligned}
$$




$$
\gamma>\frac{\left(8-8 d^{2}+d^{4}\right) t^{2}}{\left(1-d^{2}\right)\left(4-d^{2}\right)^{2}}>\frac{\left(2-d^{2}\right)^{2} t^{2}}{\left(1-d^{2}\right)\left(4-d^{2}\right)^{2}}
$$

